\title{
The Affective Profiles in the USA: Happiness, Depression, Life Satisfaction, and Happiness-Increasing Strategies
}

Background. The affective profile model categorizes individuals as self-fulfilling (high positive affect, low negative affect), high affective (high positive affect, high negative affect), low affective (low positive affect, low negative affect), and self-destructive (low positive affect, high negative affect). The model has been used extensively among Swedes to discern differences between profiles regarding happiness, depression, and also life satisfaction. The aim of the present study was to investigate such differences in a sample of residents of the USA. The study also investigated differences between profiles with regard to happiness-increasing strategies.

Methods. In Study I, 900 participants reported affect (Positive Affect Negative Affect Schedule; PANAS) and happiness (Happiness-Depression Scale). In Study II, 500 participants self-reported affect (PANAS), life satisfaction (Satisfaction With Life Scale), and how often they used specific strategies to increase their own happiness (Happiness-Increasing Strategies Scales).

Results. The results showed that, compared to the other profiles, self-fulfilling individuals were less depressed, happier, and more satisfied with their lives. Nevertheless, self-destructive were more depressed, unhappier, and less satisfied that all other profiles. The self-fulfilling individuals tended to use strategies related to agentic (e.g., instrumental goal-pursuit), communal (e.g., social affiliation), and spiritual (e.g., religion) values when pursuing happiness.

Conclusion. These differences suggest that promoting positive emotions can positively influence a depressive-to-happy state as well as increasing life satisfaction. Moreover, the present study shows that pursuing happiness through strategies guided by agency, communion, and spirituality is related to a self-fulfilling experience described as high positive affect and low negative affect. 
9 Erica Schütz ${ }^{1,2,3}$, Uta Sailer ${ }^{1,3}$, Ali Al Nima ${ }^{1,3}$, Patricia Rosenberg ${ }^{3}$, Ann-Christine Andersson

$$
\text { Arntén }{ }^{1,3}, \text { Trevor Archer }{ }^{1,2,3} \text {, Danilo Garcia }{ }^{3,4,5 *}
$$

${ }^{1}$ Department of Psychology, University of Gothenburg, Gothenburg, Sweden

${ }^{2}$ Department of Psychology, Linneaus University, Kalmar, Sweden

${ }^{3}$ Network for Empowerment and Well-Being, Sweden

$11{ }^{4}$ Center for Ethics, Law and Mental Health (CELAM), University of Gothenburg, Gothenburg,

Sweden

135 Institute of Neuroscience and Physiology, The Sahlgrenska Academy, University of Gothenburg, Gothenburg, Sweden

$20 *$ Correspondence concerning this article should be addressed to D. Garcia, CELAM, University

21 of Gothenburg, Wallinsgatan 8, SE 43141 Mölndal, Sweden. E-mail: 
danilo.garcia@neuro.gu.se; danilo.garcia@euromail.se.

\section{Introduction}

24 Besides being markers of well-being (Diener, 1984), positive (PA) and negative affect (NA) have

25 been shown to reflect stable emotional-temperamental dispositions (e.g., Watson and Clark, 1994:

26 Tellegen, 1993). Larsen and Ketelaar (1991), for example, showed that individuals who

27 experience high levels of PA, compared to individuals who experience low levels of PA, attend

28 and react more intensely to positive stimuli. Likewise, individuals who experience high levels of

29 NA, compared to individuals who experience low levels of NA, attend and react more intensely

30 to negative stimuli (see also Norris, Larsen and Cacioppo, 2007; Lucas, 2008; Lucas and Diener,

31 2008). One of the most used instruments to measure affect, is the Positive Affect and Negative

32 Affect Schedule (PANAS; Watson, Clark and Tellegen, 1988), which was developed on the idea

33 that PA and NA represents two orthogonal independent dimensions: high PA versus low PA and

34 high NA versus low NA (see also Watson and Tellegen, 1985).

Presenting affect as being composed of two systems, each one of them categorized as high

36 and low, leads to four different combinations beyond the two-system approach (Garcia, 2011; for

37 a point of view on two-system theories see Keren and Schul, 2009). In this line of thinking,

38 Archer and colleagues have developed the affective profile model through self-reported

39 affectivity using the PANAS, generating four different profiles: self-fulfilling (high PA, low

40 NA,); high affective (high PA, high NA); low affective (low PA, low NA); and self-destructive

41 (low PA, high NA) (e.g., Norlander, Bood and Archer, 2002; Bood, Archer and Norlander, 2004;

42 Norlander, Johansson and Bood, 2005; Archer, Adriansson, Plancak and Karlsson, 2007;

43 Karlsson and Archer, 2007; Palomo, Kostrzewa, Beninger and Archer, 2007; Palomo, Beninger,

44 Kostrzewa, and Archer, 2008; Archer, Adolfsson and Karlsson, 2008).

45 Self-fulfilling individuals report feeling more energetic and optimistic than the other three

46 affective profiles (Archer et al., 2007), while all four profiles react differently to stress and have 
47 different exercise habits and blood pressure. Self-fulfilling and high affective individuals show

48 the best performance during stress, have a more active life, and lower blood pressure than

49 individuals with low affective and self-destructive profiles (Norlander et al., 2002; 2005).

50 Nevertheless, Kunst (2011) showed that high affective profiles, as self-destructive profiles, were

51 strongly associated with increased posttraumatic stress disorder symptoms severity (for similar

52 results among psychiatric patients see Zöller and Archer, 2009; Zöller, Karlsson and Archer,

53 2009). Moreover, while low affective profiles have responded maladaptively to induced stress,

54 compared to self-fulfilling and high affective individuals (Norlander et al., 2002), they have at the

55 same time reported less stress in their life, as the self-fulfilling profiles (Norlander et al., 2005).

56 Thus, the affective profile model offers something unique over and above the single dimensional

57 framework by taking into account how both dimension interact. These interactions can be used to

58 investigate individual differences in cognitive and emotional aspects of health and well-being (for

59 a review see Garcia, Ghiabi, Moradi, Siddiqui \& Archer, 2013).

60

Most past research using the affective profile model among adults has focused on

61 measures of ill-being. Nevertheless, other important aspects of mental health are positive

62 measures of well-being (Cloninger, 2006). Happiness, for example, can be usefully understood as

63 the opposite end of depression (e.g., Joseph, Linley, Harwood, Lewis \& McCollam, 2004; Russell

64 and Feldman Barrett, 1999; Watson, Wiese, Vaidya, and Tellegen, 1999; Yik, Russell, and

65 Feldman Barrett, 1999). Life satisfaction, another positive measure of well-being (Diener, 1984;

66 Bradburn, 1969; Diener, Suh, Lucas and Smith, 1999; Pavot, 2008), refers instead to a

67 comparison process in which individuals assess the quality of their lives on the basis of their own

68 self-imposed standard (Pavot \& Diener, 1993).

69 Recent studies among adolescents have, indeed, focused on differences among profiles

70 with respect to different measures of well-being, personality and self-regulation (e.g., Garcia and

71 Siddiqui, 2009a b; Garcia, Rosenberg, Erlandsson and Siddiqui, 2010; Garcia, 2009, 2011, 
72 2012a; Garcia and Archer, 2012; Garcia, Kerekes, Andersson-Arntén, and Archer, 2012; Garcia,

73 2013). Garcia and colleagues have found that, compared to the other profiles, individuals with a

74 self-fulfilling profile reported higher satisfaction with life, higher psychological well-being,

75 lower depressive symptoms, and scored higher in personality traits related to agentic values (i.e.,

76 autonomy, responsibility, self-acceptance, intern locus of control, self-control). Nevertheless, low

77 affective individuals, compared to self-destructives, have reported being more satisfied with life

78 and experiencing higher levels of psychological well-being (e.g., Garcia and Siddiqui, 2009b).

79 These specific findings are also in line with the observations that low affectives and self-fulfilling

80 individuals, report less stress in their lives (Norlander et al., 2005). Moreover, Garcia (2012a)

81 also showed that high affective and self-destructive profiles, compared to self-fulfilling and low

82 affectives, scored higher on Neuroticism. This is not surprising, because Neuroticism is almost

83 synonymous with negative affectivity (Watson and Clark, 1984; Tellegen, 1985) — both the high

84 affective and self-destructive profiles have high levels of NA as a common characteristic, PA is

85 instead suggested as strongly positively related to Extraversion. These differences in personality

86 and well-being among profiles are suggested to, in accordance to Higgins' (1997) prevention and

87 promotion focus principles, result in differences in how individuals increase their happiness

88 levels (i.e., by approaching happiness or avoiding unhappiness). Although there are current

89 measures of happiness-increasing strategies, this suggestion has not been investigated in earlier

90 research using the affective profiles model.

91 Happiness-Increasing Strategies

92 In order to intentionally pursue happiness, people seem to use different strategies. Tkach and

93 Lyubomirsky (2006) have identified, using first an open-ended survey, 53 happiness-increasing

94 strategies used by residents of the USA (for studies using this scale among Swedes see, Garcia,

95 2012b; Nima, Archer and Garcia, 2012, 2013). Tkach and Lyubomirsky (2006) found, using 
96 factor analysis, eight factors: Social Affiliation (e.g. "Support and encourage friends"), Partying

97 and Clubbing (e.g. "Drink alcohol”), Mental Control (e.g. "Try not to think obout being

98 unhappy"), Instrumental Goal Pursuit (e.g. "Study"), Passive Leisure (e.g. "Surf the internet"),

99 Active Leisure (e.g. "Exercise”), Religion (e.g. "Seek support from faith") and Direct Attempts

100 (e.g. “Act happy/smile, etc.”).

101 Results have shown that these happiness-increasing strategies accounted for $52 \%$ of the

102 variance in happiness, while the Big Five personality traits, which traditionally have been linked

103 to happiness, accounted for $46 \%$. Further, even after controlling for the contribution of

104 personality, the happiness-increasing strategies accounted for $16 \%$ of the variance in happiness.

105 However, these relationships might not be a direct one. For example, Extraversion, which is

106 strongly related to high PA (Larsen \& Ketelaar, 1991), is related to the use of the Social

107 Affiliation strategy, which, in turn, is related to happiness. Tkach and Lyubomirsky (2006)

108 suggested that the efficacy of the happiness-increasing strategies is also likely to vary to some

109 extent. However, the strategy that was the most robust predictor of low levels of happiness was

110 Mental Control, which was closely related to Neuroticism. This strategy is defined as ambivalent

111 intentional efforts aimed, on one side and avoidance of negative thoughts and feelings as well as

112 proneness towards contemplation of negative aspects of life on the other. Regarding the affective

113 profiles, if the profiles differ in the way they pursue happiness (i.e., approaching happy

114 experiences versus preventing unhappy experiences), then it could be expected that the profiles

115 differ in the use of the strategies described here. For example, it could be expected that high PA

116 profiles should score higher in strategies such as Social Affiliation and Active Leisure due to the

117 close positive relationship between Extraversion and PA. High NA profiles could be expected to

118 score higher in strategies such as Mental Control, because the positive relationship between

119 Neuroticism and NA.

\section{The present study}


121 To the best of our knowledge, the affective profiles model has been mostly used among Swedish

122 participants. Some cultures explain the world as good and controllable and others emphasize

123 negative emotions as normal (Myers \& Diener, 1995; Diener, Suh and Oishi, 1997). In this

124 context, it is interesting noticing that the right to pursuit individual happiness is listed as an

125 absolute right in the United States of America's declaration of independence (Tkach and

126 Lyubomirsky, 2006). The model, however, has shown identical results in the few studies using

127 other populations (for three studies using Dutch, Indonesian, respectively Iranian participants see

128 Kunst, 2011; Adrianson, Djamaludin, Neila and Archer, 2013; Garcia and Moradi, 2013).

129 The aim of the present study was to investigate differences in happiness, depression, life

130 satisfaction and use of strategies to increase happiness among affective profiles in residents of the

131 United States of America (US-residents).

\section{Study I}

\section{Method}

\section{Ethics statement}

135 This research protocol was approved by the Ethics Committee of the University of Gothenburg

136 and written informed consent was obtained from all the study participants.

\section{Participants and procedure}

138 The participants $(N=900$, age mean $=28.72 s d .=19.10,550$ males and 350 females $)$ were US-

139 residents recruited through Amazons' Mechanical Turk (MTurk;

140 https://www.mturk.com/mturk/welcome). MTurk allows data collectors to recruit participants

141 (workers) online for completing different tasks in change for wages. This method for data

142 collection online has become more common during recent years and it is an empirical tested valid

143 tool for conducting research in the social sciences (see Buhrmester, Kwang \& Gosling, 2011).

144 Participants were recruited by the following criteria: US-resident and to both speak and write

145 fluent in English. Participants were paid a wage of two American dollars for completing the task 
146 and informed that the study was confidential and voluntary. The participants were presented with

147 a battery of self-reports comprising the affect and happiness measures, as well as questions

148 pertaining age and gender.

\section{Instruments}

150 Positive Affect and Negative Affect Schedule (PANAS; Watson et al., 1988). The PANAS instructs

151 participants to rate to what extent they generally have experienced 20 different feelings or

152 emotions (10 PA and $10 \mathrm{NA})$ during the last weeks, using a 5-point Likert scale (1 = very slightly,

1535 =extremely). The 10-item PA scale includes adjectives such as strong, proud, and interested.

154 The 10- item NA scale includes adjectives such as afraid, ashamed and nervous. Cronbach's $\alpha$ 155 were .87 for PA and .89 for NA in the present study.

156 The Short Depression-Happiness Scale (Joseph et al., 2004). This instrument consists of

157 six items, three items measuring happiness (e.g., "I felt happy") and three reverse coded items

158 measuring depressive states (e.g., "I felt my life was meaningless"). Participants rate how

159 frequently they feel the way described in the item on a four-point scale: "never", "rarely",

160 "sometimes", "often". In the present study, Cronbach's $\alpha$ was .85 for the happiness scale and .76

161 for the depression scale.

\section{Statistical treatment}

163 We used participants' self-reported affect measured by the PANAS from both Study I and $2(N=$

$1641,400)$ in order to classify participants in the four affective profiles. Participants' PA and NA

165 scores were divided into high and low (cut-off points: low PA $=3.0$ or less; high PA $=3.1$ or

166 above; low NA $=1.8$ or less; and high NA $=1.9$ or above).

167 For Study I, the two independent variables of the study were gender and affective profile:

168 self-fulfilling ( $n=241 ; 153$ males, 88 females), low affective ( $n=236 ; 137$ males, 99 females),

169 high affective ( $n=180 ; 115$ males, 65 females), and self-destructive ( $n=243 ; 145$ males, 98

170 females). The dependent variables were PA, NA, happiness, and depression. 


\section{Results and discussion}

172 A Multiple Analysis of Variance (MANOVA) indicated a significant effect for gender $(F(4,889)$

$173=4.32 ; p=.002, E t a^{2}=0.02$, power $\left.=0.93\right)$ as well as for affective profile $(F(12,2673)=$

$174162.19 ; p<.001, E t a^{2}=0.42$, power $\left.=1.00\right)$. The interaction of gender and affective profile was

175 not significant $(p=.236)$. A between-subjects ANOVA showed an significant gender effects for

176 happiness $(F(1,892)=7.60 ; p=0.006)$, whereby the female participants expressed a higher level

177 of happiness $(M=9.66, S D=2.13)$ than the male participants $(M=9.35, S D=2.33)$.

178 A between-subject ANOVA indicated significant affective profile effects for PA $(F(3,892)$

$179=513.78 ; p<.001), \mathrm{NA}(F(3,892)=503.58 ; p<.001)$, happiness $(F(3,892)=68.20 ; p<.001)$,

180 and depression $(F(3,892)=71.50 ; p<.001)$. A Bonferroni correction to the alpha level of .01

181 showed that the self-destructive group had significantly higher scores in NA and depression as

182 well as lower scores in happiness in comparison to the other affective profiles. The self-fulfilling

183 group differed significantly from the self-destructive profiles in all measured variables; PA, NA,

184 happiness and depression. As expected, the high affective ones differed significantly from the 185 self-fulfilling group in all variables except PA and the low affective ones differed significantly

186 from the self-fulfilling group in all variables except NA. Which is not so strange since both the

187 self-fulfilling group and the high affective group are characterized as high in PA and the same 188 goes for self-fulfilling individuals and low affective individuals who are characterized by low

189 NA. For further details, see table 1.

190

Table 1 here

191

\section{Study II}

192 Method

193 Participants and procedure

194 As in Study I, participants $(N=500$, age mean $=34.08 s d .=12.55 ; 217$ male and 283 female $)$ 
195 were recruited from MTurk by the following criteria: resident of the USA and to both speak and

196 write fluent in English. Participants were paid a wage of two American dollars for completing the

197 task and informed that the study was confidential and voluntary. The participants were presented

198 with a battery of self-reports comprising the affect, life satisfaction, and happiness-increasing

199 strategies measures, as well as questions pertaining age and gender.

Instruments

201 The same instrument as in Study I was used in Study II to measure PA and NA (i.e., the PANAS).

202 Cronbach's $\alpha$ were .88 for PA and .90 for NA in Study II.

Satisfaction with Life Scale (Diener, Emmons, Larsen and Griffin, 1985). The instrument

consists of 5 statements (e.g., "In most of my ways my life is close to my ideal") for which

participants are asked to indicate degree of agreement in a 7-point Likert scale $(1=$ strongly

206 disagree, $7=$ strongly agree). The life satisfaction score was established by summarizing the 5

207 statements for each participant. Cronbach's $\alpha$ were .90 in the present study.

208 Happiness-Increasing Strategies Scales (Tkach and Lyubomirsky, 2006). In the present

209 study, participants were asked to rate $(1=$ never, 7 = all the time $)$ how often they used the

210 strategies identified by Tkach and Lyubomirsky (2006). The happiness-increasing strategies are

211 organized in eight clusters: Social Affiliation (e.g., "Support and encourage friends"; Cronbach's

$212 \alpha=0.79$ ), Partying and Clubbing (e.g., "Drink alcohol"; Cronbach's $\alpha=0.74)$, Mental Control

213 (e.g., "Try not to think about being unhappy"; Cronbach's $\alpha=0.43$ ), Instrumental Goal Pursuit

214 (e.g. "Study"; Cronbach's $\alpha=0.76$ ), Passive Leisure (e.g. "Surf the internet"; Cronbach's $\alpha=$

215 0.63), Active Leisure (e.g. "Exercise”; Cronbach's $\alpha=0.65)$, Religion (e.g. "Seek support from

216 faith"; Cronbach's $\alpha=0.70$ ), and Direct Attempts (e.g. "Act happy/smile, etc."; Cronbach's $\alpha=$

217 0.56).

218 Statistical treatment

219 As detailed in Study I, both samples were used in the classification of the four affective profiles. 
220 The number of participants in each profile for Study II were as follows: 158 self-fulfilling (75

221 males, 83 females), 92 low affective (42 males, 50 females), 123 high affective (54 males, 69

222 females), and 127 self-destructive (46 males, 81 females). The affective profiles and gender were

223 the independent variables, PA, NA, life satisfaction, and the happiness-increasing strategies were

224 the dependent variables. An important observation here is the gender distribution between

225 profiles. For example, in Study I there were more self-destructive males than females, while in

226 Study II there were more self-destructive females than males. This difference might mirror the

227 gender distribution across Study I (550 males and 350 females) and Study II (217 male and 283

228 females). Across both samples of females, the prevalence of the self-destructive profile was $28 \%$,

229 while among men was $25 \%$. The prevalence of this profile reported here among males and

230 females is the same that was observed among Swedes (Schütz, Garcia \& Archer, 2013).

231 Results and discussion

232 First a MANOVA ( $3 \times 2$ factorial design) was applied with affective profiles and gender as

233 independent variables and with PA, NA and life satisfaction as dependent variables. The analysis

234 did not indicate any significant interaction effect $(p=0.14)$, but did indicate a significant effect

235 for gender $\left(F(3,490)=4.91 ; p<0.01, E t a^{2}=0.03\right.$, power $\left.=0.91\right)$ as well as for affective profiles

$236\left(F(9,1476)=119.15 ; p<0.001, E_{t a}^{2}=0.42\right.$, power $\left.=1.00\right)$. Secondly, a MANOVA $(1 \times 2$

237 factorial design) was applied with affective profiles and gender as independent variables and with

238 happiness-increasing strategies as dependent variables. The analysis did not indicate any

239 significant interaction effect $(p=0.93)$, but did indicate a significant effect for gender $(F(8,485)$

$240=5.85 ; p<0.001, E t a^{2}=0.09$, power $\left.=1.00\right)$ as well as for affective profiles $(F(24,1461)=8.64$;

$241 p<0.001, E_{t a}^{2}=0.12$, power $\left.=1.00\right)$.

242

A between-subjects ANOVA was conducted in order to test gender differences in PA, NA

243 and life satisfaction. The result indicated significant gender effects for: $\mathrm{NA}(F(1,492)=10.89 ; p$ 
$244<0.01)$, whereby the female participants expressed a higher level of NA $(M=1.94, S D=0.83)$

245 than the male participants $(M=1.72, S D=0.67)$. This specific result stands in contrast to the

246 results from Study I, which showed that females reported higher happiness than males.

247 Nevertheless, this is a well-known paradox in the literature-females seem to experience positive

248 and negative emotions equally intensive, explaining why female often report both experiencing

249 more negative moods and depressive symptoms and also higher levels of happiness than males

250 (Fujita, Diener \& Sandvik, 1991). A between-subjects ANOVA was conducted to investigate

251 gender differences in happiness-increasing strategies. The result indicated significant gender

252 effects for: Social Affiliation $(F(1,492)=17.67 ; p<0.001)$, whereby the female participants

253 expressed a higher level of Social Affiliation $(M=3.43, S D=0.56)$ than the male participants $(M$

$254=3.27, S D=0.65)$; Instrumental Goal Pursuit $(F(1,492)=6.60 ; p<0.01)$, whereby the female

255 participants expressed a higher level of Instrumental Goal Pursuit $(M=3.33, S D=0.81)$ than the

256 male participants $(M=3.19, S D=0.82)$; Religion $(F(1,492)=23.18 ; p<0.001)$, whereby the

257 female participants expressed a higher Religion $(M=3.08, S D=1.13)$ than the male participants

$258(M=2.63, S D=1.04)$; Passive Leisure $(F(1,492)=9.25 ; p<0.01)$, whereby the female

259 participants expressed a higher level of Passive Leisure $(M=3.30, S D=0.55)$ than the male

260 participants $(M=3.16, S D=0.60)$; Direct Attempts $(F(1,492)=4.06 ; p<0.05)$, whereby the

261 female participants expressed a higher level of Direct Attempts $(M=3.66, S D=0.58)$ than the

262 male participants $(M=3.60, S D=0.64)$. The differences presented here are a replication of the

263 original study conducted by Tkach and Lyubomirsky (2006): females focus on behaviour such as

264 maintaining relationships (i.e., Social Affiliation), pursuing career goals (i.e., Instrumental Goal

265 Pursuit), performing religious activities (i.e., Religion), and watching TV (i.e., Passive Leisure)

266 more frequently than males when they try to increase their happiness. As suggested by Tkach and

267 Lyubomirsky (2006, pp. 214), the gender differences replicated here "are consistent with the 
gender differences reported for behaviors used to combat bad moods (Thayer et al., 1994)".

In order to test differences in life satisfaction for each of the four affective profiles a

270

271

272

273

274

between-subject ANOVA was conducted The result indicated significant effects for life satisfaction $(F(3,492)=49.26 ; p<0.001)$. Further, a between-subject ANOVA was conducted in order to test differences in happiness-increasing strategies for each of the four affective profiles. The mean scores of life satisfaction as well as for happiness-increasing strategies for all four affective profiles are presented in Table 2 .

\section{Table 2 here}

A Bonferroni test, with alpha level set to .01, was conducted to compare the mean differences in life satisfaction as well as for happiness-increasing strategies between affective profiles. The results showed, replicating earlier findings, among Swedes, that that the selfdestructive group had lower scores in life satisfaction compared to all the other affective profiles. The self-fulfilling group had higher scores in life satisfaction compared to all the other affective profiles. Regarding happiness-increasing strategies the results showed that that the selfdestructive group had lower scores in all happiness-increasing strategies except for Mental Control. For further details, see Table 3.

Table 3 here

\section{General discussion}

The aim of this set of studies was to examine the connections between the four types of affective profiles (self-fulfilling, high affective, low affective, self-destructive) to happiness and depression (Study I), satisfaction with life and happiness-increasing strategies (Study II) in US-residents.

The results showed that the self-fulfilling group reported a significantly higher level of happiness and a significantly lower level of depression than all the three other groups (high affective, low affective, self-destructive). Furthermore, the self-destructive group reported a significantly higher 
292 level of depression and lower level of happiness than all the other three groups (self-fulfilling,

293 high and low affective). The results also show that the high affective and low affective reported

294 higher level of happiness and lower level of depression than the self-destructive group. But at the

295 same time these groups (high and low affective) also showed significantly lower levels of

296 happiness and significantly higher levels depression than the self-fulfilling group. As suggested

297 by Garcia (2011), low PA among low affectives seems to influence happiness negatively as high

298 NA influences happiness negatively among high affectives. The results presented here are

299 corresponding to the results found in research with Swedish populations showing that high PA is

300 related to less stress, depression, and anxiety (e.g., Garcia et al., 2012; Lindahl \& Archer, 2013;

301 Nima, Rosenberg, Archer \& Garcia, 2013). Moreover, self-fulfilling, high affective and low

302 affective participants all have higher life satisfaction compared with self-destructive participants.

303 This result also replicates findings among Swedish pupils where self-fulfilling, high and low

304 affective participants showed higher level of life satisfaction compared with self-destructives

305 (e.g., Garcia \& Archer, 2012). As suggested by Lindahl and Archer (2013; see also Archer \&

306 Kostrzewa, 2013; Archer, Oscar-Berman, Blum \& Gold, 2013), positive affect might serve as an

307 anti-depressive factor and, as suggested here, also as protective factor for happiness and life

308 satisfaction.

309 The self-fulfilling participants showed significantly higher results than all other profiles

310 on the direct attempts strategy. Suggesting that in order to increase their happiness the self-

311 fulfilling individuals are more prone to directly attempt to smile, get them selves in a happy

312 mood, improve their social skills, and work on their self-control. Indeed, Garcia (2012a) showed

313 that self-fulfilling score higher in personality traits related to agentic values (i.e., autonomy,

314 responsibility, self-acceptance, intern locus of control, self-control) as measured by the

315 Temperament and Character Inventory (Cloninger, Svrakic \& Przybeck, 1993). Moreover, self-

316 fulfilling individuals scored lower than high NA individuals (high affectives and self- 
317 destructives) in the strategy of mental control. The mental control scale has been defined as

318 ambivalent behavior, that is, the individual using this happiness-increasing strategy make efforts

319 to avoid negative experiences by suppressing negative thoughts and feelings but also ruminating

320 about negative aspects of life (Tkach and Lyubomirsky, 2006). These tendencies may not only

321 prolong unhappiness, suppressing negative thoughts actually may end up in maintaining these

322 thoughts and thereby aggravate negative affect (Tkach \& Lyubomirsky, 2006), which may

323 explain why these tendencies are more frequent among high affective and self-destructive than

324 self-fulfilling individuals.

325 Compared to low PA individuals (i.e., low affectives and self-destructives), the self-

326 fulfilling individuals also reported using more often three of the other happiness-increasing

327 strategies: social affiliation, instrumental goal pursuit, active leisure. Social affiliations activities

328 comprise communal (i.e., cooperation) values to guide behavior such as: supporting and

329 encouraging friends, helping others, trying to improve one self, interacting with friends, and

330 receiving help from friends (Tkach \& Lyubomirsky, 2006). Instrumental goal pursuit includes

331 activities directed to achieving goals by trying to reach one's full potential, studying, organizing

332 one's life and goals, and striving for the accomplishment of tasks (Tkach \& Lyubomirsky, 2006).

333 Finally, the use of active leisure comprises a proness to wellness through fitness and flow, that is,

334 exercising and working on hobbies or activities in which the individual uses her/his strengths and

335 becomes absorbed by the activity itself (Tkach \& Lyubomirsky, 2006). In other words, both

336 instrumental goal pursuit and active leisure comprises agentic (i.e., autonomous, self-directed)

337 values guiding behavior in order to approach well-being. Indeed, among Swedes (Nima et al.,

338 2012, 2013), these three strategies (social affiliation, instrumental goal pursuit, and active leisure)

339 have been found to be positively related to subjective well-being. Agency and cooperation are

340 also related to mental health, dysfunction and suffering (Cloninger \& Zohar, 2011; Garcia,

341 Anckarsäter \& Lundström, 2013; Garcia, Lundströ̈, Brä̈dström, Raștam, Cloninger, et al., 
342 2013; Garcia, Nima \& Archer, 2013) and are suggested to help the individual to become happier

343 and healthier (Cloninger, 2013; see also Johansson Lyssarides, Andersson \& Rousseau, 2013,

344 who showed that increases in agency and cooperation are associated to improvement in

345 depression). Moreover, compared to the self-destructives, the self-fulfilling individuals reported

346 more frequently seeking support from faith, performing religious activities, praying, and drinking

347 less alcohol (i.e., the religion happiness-increasing strategy). Indeed, Cloninger (2013) has

348 suggested that while agency and cooperation might lead to happiness and health, spiritual values

349 might be needed for becoming a self-fulfilled individual that lives in harmony with the changing

350 world. See Figure 1 for a summary of the results.

351

Figure 1 should be here

\section{Limitations and future research}

353 One limitation of the present set of studies is that the results are based on MTurk workers' self-

354 reports. Nevertheless, consistent with earlier research suggesting MTurk as a valid tool for

355 collecting data using personality scales (Buhrmester et al., 2011), other researchers have found

356 that health measures using MTurk data shows satisfactory internal reliability and test-retest

357 reliability (Shapiro, Chandler \& Mueller, 2013). Furthermore, the prevalence of depression

358 among MTurk workers matches the prevalence of this illness in the general population; which

359 makes MTurk a valid tool even for clinical research (Shapiro et al., 2013). The measures used

360 here are validated and reliable measures of happiness, depression, life satisfaction, and affect;

361 however, there are other established measures that could have been used for the measurement of

362 depression (e.g., The Patient Health Questionnaire; Kroenke, Spitzer \& Williams, 2001). The

363 Short Depression-Happiness Scale (Joseph et al., 2004), used in Study I, was found appropriate

364 firstly because it was developed as a short easy-to-distribute scale based on the increasing

365 awareness of the therapeutic potential of the positive psychological perspective (e.g. Cloninger,

366 2006, Joseph \& Linley, 2004; Keyes \& Lopez, 2002). This scale has shown good psychometric 
367 properties of internal consistency reliability (Cronbach's $\alpha$ between .77-92), test-retest reliability

$368(\mathrm{r}=.68$ in a 2-week interval), and convergent and discriminant validity with measures of

369 depression (Beck's Depression Inventory), happiness (Oxford's Happiness Inventory) and

370 personality (NEO Five Factor Inventory) (Joseph et al., 2004).

371 The lack of studies in adult populations using the affective profiles model and positive

372 measures of well-being did not permit comparison of the results presented to other than earlier

373 research among adolescents and young adults, thus, showing the need for further studies on

374 adults regarding these factors. The reliability coefficients for some of the happiness-increasing

375 strategies were low (e.g., Direct Attempts showed an Cronbach's alpha $=.56$ ). In studies among

376 Swedes this scales have been modified through factor analyses (Nima et al., 2013). Although

377 most of the scales in the present study showed alphas above .63, further studies focusing in the

378 validation of these scales are needed. Furthermore, specific emotions vary widely across the

379 lifespan. Findings among men and women in the US, for example, show that as people age they

380 become less stressed and angry, although worry seems to persist as a negative emotion in peoples

381 lives during middle age (Stone, Schwartz, Broderick \& Deaton, 2010). Positive emotions such as

382 happiness and enjoyment along with negative emotions such as sadness, however, show very

383 limited change with age (Stone et al., 2010). Although the present study did not aim to investigate

384 variations in specific emotions with respect to age, further studies exploring increases/decreases

385 in PA and NA are needed.

386 Finally, since median splits distort the meaning of high and low, it is plausible to criticize

387 the validity of the procedure used here to create the different affective profiles — scores just-above

388 and just-below the median become high and low by fiat, not by reality (Schütz, Archer \& Garcia,

389 2013). Nevertheless, a recent study (MacDonald \& Kormi-Nouri, 2013) used k-means cluster

390 analysis to test if the affective profiles model emerged as theorized by Archer and colleagues. The 
391 affective profile model was replicated using the k-means cluster analysis and the four affective

392 profiles emerged as the combinations of high vs. low affectivity. The procedure used by these

393 researchers is useful for person-oriented analyses (see Bergman, Magnusson et al., 2003), thus,

394 suggesting the original procedure by Archer as valid.

395

396

397

\section{Conclusion}

398 The present set of studies expands earlier results among Swedes to a relative large sample of US-

399 residents. The results suggest that the affective profile model distinguish important differences in

400 happiness, depression, and life satisfaction between individuals. These differences suggest that

401 promoting positive emotions can positively influence a depressive-to-happy state as well as

402 increasing life satisfaction. Moreover, the present study describes further how affective profiles

403 differ with regard to happiness-increasing strategies. These specific results suggest that the

404 pursue of happiness through agentic, communal, and spiritual values leads to a self-fulfilling

405 experience defined as frequently experiencing positive emotions and infrequently experiencing

406 negative emotions.

407 "It was right then that I started thinking about

408 Thomas Jefferson on the Declaration of Independence

409 and the part about our right to life, liberty, and

410 the pursuit of happiness. And I remember thinking

411 how did he know to put the pursuit part in there?"

412 Will Smith as Christopher Gardner in The Pursuit of Happyness

413

414 
421 Legends and Captions

422 Table 1. Mean scores in PA, NA, happiness, and depression for each affective profile in Study I.

423 Table 2. Means in life satisfaction and happiness-increasing strategies among affective profiles in 424 Study II.

425 Table 3. Mean differences in life satisfaction and happiness-increasing strategies between 426 affective profiles.

427 Figure 1. Summary of the results from Study I and II showing the differences between affective 428 profiles in happiness, depression, life satisfaction, and the happiness-increasing strategies. 


\section{References}

445 Adrianson, L., Djumaludin, A., Neila, R., \& Archer, T. (2013). Cultural influences upon health, affect, self-esteem and impulsiveness: An Indonesian-Swedish comparison. International Journal of Research Studies in Psychology. DOI: 10.5861/ijrsp.2013.228.

448 Archer, T., Adolfsson, B., \& Karlsson, E. (2008). Affective personality as cognitive-emotional presymptom profiles regulatory for self-reported health predispositions. Neurotoxicity Research, 14, 21-44.

Archer, T., Adrianson, L., Plancak, A., \& Karlsson, E. (2007). Influence of affective personality on cog- nitive-mediated emotional processing: Need for empowerment. European Journal

Archer, T., \& Kostrzewa, R. M. (2013). The inductive agency of stress: From periatal to of Psychiatry, 21, 21-44. adolescent induction. In G. Laviola \& S. Macr`1 (Eds.), Adaptive and maladaptive aspects of developmental stress, current topics in neurotoxicity (Vol. 3, pp. 1-20). New York: disorders. Journal of Genetic Syndromes \& Gene Therapy, 4, 120-133. doi:10.4172/21577412.1000120 . 
463 Bood, S. Å., Archer, T., \& Norlander, T. (2004). Affective personality in relation to general personality, self-reported stress, coping and optimism. Individual Differences Research, 2, 26-37.

466 Bradburn, N. M. (1969). The structure of psychological well-being. Chicago: Aldine.

467 Buhrmester, M. D., Kwang, T., \& Gosling, S. D. (2011). Amazon's Mechanical Turk: A New 468 Source of Inexpensive, yet High-Quality, Data? Perspectives on Psychological Science, 6, $469 \quad 3-5$.

470 Cloninger, C. R. (2004). Feeling good: The science of well-being. New York: Oxford University Press.

472 Cloninger, C. R. (2006). Fostering spirituality and well-being in clinical practice. Psychiatric 473 Annals, 36, 1-6.

474 Cloninger, C. R. (2013). What makes people healthy, happy, and fulfilled in the face of current 475 world challenges? Mens Sana Monographs, 1, 16-24.

Cloninger, C. R., Svrakic, D. M., \& Przybeck, T. R. (1993). A Psychobiological model of temperament and character. Archives of General Psychiatry, 50, 975-989.

Cloninger, C. R., \& Zohar, A. H. (2011). Personality and the perception of health and happiness.

479 Journal of Affective Disorders, 128, 24-32.

480 Diener, E (1984). Subjective well-being. Psychological Bulletin, 95, 542-575.

481 Diener, E., Emmons, R. A., Larsen, R. J., \& Griffin, S. (1985). The satisfaction with life scale. $482 \quad$ Journal of Personality Assessment, 49, 71-75.

483 Diener, E., Suh, E. M., Lucas, R. E., and Smith, H. L. (1999) Subjective well-being: Three 484 decades of progress. Psychological Bulletin, 125, 276-302

485 Diener, E, Suh, E. \& Oishi, S. (1997). Recent findings on subjective well being. Indian Journal 486 of Clinical Psychology, 24, 25-41.

487 Fujita, F., Diener, E., Sandvik, E. (1991). Gender differences in negative affect and well- being: 
The case for emotional intensity. Journal of Personality and Social Psychology, 61, 427434.

490 Garcia, D. (2009). Interpretation and Recognition for Words in a Short Story [Database record]. Retrieved from the American Psychological Association's PsycTESTS. DOI:

Garcia, D. (2011) Adolescents' happiness: The role of the affective temperament model on Conference on Positive Psychology, Moscow, 26-29 June 2012, 34. memory and apprehension of events, subjective well-being, and psychological well-being. Ph.D. Thesis, University of Gothenburg, Gothenburg.

Garcia, D. (2012a). The Affective Temperaments: Differences between Adolescents in the Big Five Model and Cloninger's Psychobiological Model of Personality. Journal of Happiness Studies, 13, 999- 1017. DOI: 10.1007/s10902-011-9303-5.

Garcia, D. (2012b) Adolescents' happiness-increasing strategies and well-being. 6th European

Garcia, D. (2013). La vie en Rose: High Levels of Well-Being and Events Inside and Outside Autobiographical Memory. Journal of Happiness Studies. DOI: 10.1007/s10902-013-

Garcia, D., \& Archer, T. (2012). Adolescent Life Satisfaction and Well-Being. Journal of Alternative Medicine Research, 4, 271-279.

509 Garcia, D., Ghiabi, B., Moradi, S., Siddiqui, A., \& Archer, T. (2013). The Happy Personality: A

510 Tale of Two Philosophies. In E. F. Morris \& M-A. Jackson (Eds.), Psychology of

511 Personality (pp. 41-59). New York: Nova Science Publishers.

512 Garcia, D., Kerekes, N., Andersson-Arntén, A-C., \& Archer, T. (2012). Temperament, Character, 
and Adolescents’ Depressive Symptoms: Focusing on Affect. Depression Research and Treatment. DOI:10.1155/2012/925372.

515 Garcia, D., Nima, A. A., \& Archer, T. (In press). Temperament and Character's Relationship to 516 Subjective Well-Being in Salvadorian Adolescents and Young Adults. Journal of $517 \quad$ Adolescence.

518 Garcia, D., Lundström, S., Brändström, S., Råstam, M., Cloninger, C. R., Kerekes, N., Nilsson, 519 T., Anckarsäter, H. (2013). Temperament and Character in the Child and Adolescent Twin 520 Study in Sweden (CATSS): Comparison to the General Population, and Genetic Structure 521

522 Garcia, D., \& Moradi, S. (2013). The Affective Temperaments and Well-Being: Swedish and 523 Iranian Adolescents' Life Satisfaction and Psychological Well-Being. Journal of Happiness Studies, 14, 689-707. DOI: 10.1007/s10902-012-9349-z.

525 Garcia, D., \& Siddiqui, A. (2009a). Adolescents’ Affective Temperaments: Life Satisfaction, 526 Interpretation and Memory of events. The Journal of Positive Psychology, 4, 155-167.

528 Garcia, D., \& Siddiqui, A. (2009b). Adolescents' Psychological Well-Being and Memory for Life 529 Events: Influences on Life Satisfaction with Respect to Temperamental Dispositions. 530 Journal of Happiness Studies, 10, 387-503. DOI: 10.1007/s10902-008-9096-3.

531 Garcia, D., Rosenberg, P., Erlandsson, A., \& Siddiqui, A. (2010). On Lions and Adolescents: 532 Affective Temperaments and the Influence of Negative Stimuli on Memory. Journal of Happiness Studies, 11, 477-495. DOI: 10.1007/s10902-009-9153-6.

534 Higgins, E. T. (1997). Beyond pleasure and pain. American Psychologist, 52, 1280-1300.

535 Johansson, R., Lyssarides, C., Andersson, G., \& Rousseau, A. (2013). Personality change after 536 interner-delivered cognitive behavior therapy for depression. PeerJ 1:e39. DOI: 537 10.7717/peerj.39. 
538

539

540

541

542

543

544

545

546

547

548

549

550

551

552

553

554

555

556

557

558

559

560

561

Joseph, S., \& Linley, P. A. (2004). Positive therapy: A positive psychological theory of therapeutic practice. In P. A. Linley \& S. Joseph (Eds), Positive psychology in practice (pp. 354-368). Hoboken, NJ: Wiley.

Keyes, C. L. M., \& Lopez, S. J. (2002). Toward a science of mental health: Positive directions in diagnosis and interventions. In C. R. Snyder \& S. J. Lopez (Eds), Handbook of positive psychology (pp.45-59). New York: Oxford University Press.

Joseph, S., Linley, P. A., Harwood, J., Lewis, C. A., \& McCollam, P. (2004). Rapid assessment of well-being: The Short Depression-Happiness Scale. Psychology and Psychotherapy: Theory, Research, and Practice, 77, 1-14.

Karlsson, E., \& Archer, T. (2007). Relationship between personality characteristics and affect: Gender and affective personality. Individual Differences Research, 5, 44-58.

Keren, G., \& Schul, Y. (2009). Two is not always better than one. A critical evaluation of twosystem theories. Perspectives on Psychological Science, 4, 533-550.

Kunst, M. J. J. (2011). Affective personality type, post-traumatic stress disorder symptom severity and post-traumatic growth in victims of violence. Stress and Health, 27, 42-51.

Larsen, R. J., \& Ketelaar, T. (1991). Personality and susceptibility to positive and negative emotional states. Journal of Personality and Social Psychology, 61, 132-140.

Lindahl, M., \& Archer, T. (2013). Depressive expression and anti-depressive protection in adolescence: Stress, positive affect, motivation and self-efficacy. Psychology, 4, 495-505.

Lucas, R. E. (2008). Personality and Subjective Well-Being. In M. Eid, \& R.J. Larsen (Eds.). The science of subjective well-being (pp. 171-194). New York: The Guilford Press.

Lucas, R. E., \& Diener, E. (2008) Personality and Subjective Well-Being. In O. P. John, R. W. Robins, \& L. A. Pervin (Eds.). Handbook of Personality - Theory and Research (pp. 795814). New York: The Guilford Press.

562 MacDonald, S., \& Kormi-Nouri, R. (2013). The affective personality, sleep, and autobiographical 

promoting good practice, 8, 305-313.

565 Myers, D. G., \& Diener, E. (1995). Who is happy? Psychological Science, 6, 10-19.

566 Nima, A. A., Archer, T., \& Garcia, D. (2012). Adolescents' happiness-increasing Strategies, 567 Temperament, and Character: Mediation models on Subjective Well-Being. Health, 4, 568 802-810. DOI: $10.4236 /$ health.2012.410124.

569 Nima, A. A., Archer, T., \& Garcia, D. (2013). The Happiness-Increasing Strategies Scales in a 570 Sample of Swedish Adolescents. International Journal of Happiness and Development, 1 , $196-211$.

572 Nima, A. A., Rosenberg, P., Archer, T., \& Garcia, D. (2013). Anxiety, Affect, Self-esteem, and Stress: Mediation and Moderation Effects on Depression. PLOS ONE. DOI: 10.1371/journal.pone.0073265.

Norris, C. J., Larsen, J. T., \& Cacioppo, J. T. (2007). Neuroticism is associated with larger and more prolonged electrodermal responses to emotionally evocative pictures. Psychophysiology, 44, 823-826.

Norlander, T., Bood, S.-Å., \& Archer, T. (2002). Performance during stress: Affective personality age, and regularity of physical exercise. Social Behavior and Personality, 30, 495-508.

Norlander, T., Johansson, Å., \& Bood, S.-Å. (2005). The affective personality: Its relation to quality of sleep, well-being and stress. Social Behavior and Personality, 33, 709-722. than diagnoses in brain dysfunction: Conscious and nonconscious expression in impulsiveness and decision making. Neurotoxicity Research, 14, 1-20. 
588 Pavot, W. (2008). The assessment of subjective well-being: Successes and shortfalls. In M. Eid \& R. J. Larsen (Eds.), The science of subjective well-being (pp. 124-167). New York: The Guilford Press.

591 Pavot, W., \& Diener, E. (1993). Review of the satisfaction with life scale. Psychological $592 \quad$ Assessment, 2, 164-172.

593 Russell, J. A., \& Feldman Barrett, L. (1999). Core affect, prototypical emotional episodes, and other things called emotion: Dissecting the elephant. Journal of Personality and Social Psychology, 76, 805-819.

Schütz, E., Garcia, D., \& Archer, T. (2013). Affective State, Stress and Type A-personality as a Function of Gender and Affective Profiles. Manuscript under editorial evaluation.

Shapiro, D. N., Chandler, J., \& Mueller, P. A. (2013). Using Mechanical Turk to Study Clinical Populations. Clinical Psychological Science, 1, 213-220.

Stone, A. A., Schwartz, J. E., Broderick, J. E., Deaton, A. (2010). A snapshot of the age distribution of psychological well-being in the United States. PNAS, 107, 9985-9990.

Thayer, R. E., Newman, R., \& McClain, T. M. (1994). Self-regulation of mood: Strategies for changing a bad mood, raising energy, and reducing tension. Journal of Personality and

Tkach, C., \& Lyubomirsky, S. (2006) How do people pursue happiness? Relating personality, happiness-increasing strategies, and well-being. Journal of Happiness Studies, 7, 183-225.

608 Tellegen, A. (1985). Structures of mood and personality and their relevance to assessing anxiety, 609 with an emphasis on self-report. In A. H. Tuma \& J. D. Maser (Eds.), Anxiety and the Anxiety disorders, (pp. 681-706), Hilssdale, NJ: Erlbaum.

611 Tellegen, A. (1993). Folk concepts and psychological concepts of personality and personality 612 disorder. Psychological Inquiry, 4, 122-130. 
613 Watson, D., \& Clark, L. A. (1984). Negative affectivity: The disposition to experience negative 614 aversive emotional states. Psychological Bulletin, 96, 465-490.

615 Watson, D., \& Clark, L. A. (1994). The PANAS-X: Manual for the positive and negative affect 616 schedule—Expanded form. Boise: University of Iowa Press.

617 Watson, D., Clark, L. A., \& Tellegen, A. (1988). Development and validation of brief measures of 618 positive and negative affect: The PANAS scale. Journal of Personality and Social 619 Psychology, 54, 1063-1070.

620 Watson, D., \& Tellegen, A. (1985). Toward a consensual structure of mood. Psychological $621 \quad$ Bulletin, 98, 219-235.

622 Watson, D., Wiese, D., Vaidya, J., \& Tellegen, A. (1999). The two general activation systems of 623 affect: Structural findings, evolutionary considerations, and psychobiological evidence. $624 \quad$ Journal of Personality and Social Psychology, 76, 820-838.

625 Yik, M. S. M., Russell, J. A., \& Feldman Barrett, L. (1999). Structure of self reported current 626 affect: Integration and beyond. Journal of Personality and Social Psychology, 77, 600$627 \quad 619$.

628 Zöller, M., \& Archer, T. (2009). Predicting stress in male and female psychiatric patients and 629 healthy volunteers. Social Behavior and Personality, 7, 1081-1094.

630 Zöller, M., Karlsson, E., \& Archer, T. (2009). Self-rated affect among adults presenting 631 psychiatric diagnosis. Individual Differences Research, 7, 14-28. 


\section{Table $\mathbf{1}_{\text {(on next page) }}$}

Table 1

Mean scores in PA, NA, happiness, and depression for each affective profile in Study I. 
1 Table 1. Mean scores in PA, NA, happiness and depression for each affective profile in Study I.

\begin{tabular}{lcccc}
\hline & Self-fulfilling & High affective & Low affective & Self-destructive \\
& $n=241$ & $n=180$ & $n=236$ & $n=243$ \\
\hline Positive Affect & $3.66 \pm 0.44^{\mathrm{c}, \mathrm{d}}$ & $3.59 \pm 0.41^{\mathrm{c}, \mathrm{d}}$ & $2.37 \pm 0.52^{\mathrm{a}, \mathrm{b}}$ & $2.36 \pm 0.50^{\mathrm{a}, \mathrm{b}}$ \\
Negative Affect & $1.27 \pm 0.21^{\mathrm{b}, \mathrm{d}}$ & $2.20 \pm 0.51^{\mathrm{a}, \mathrm{d}}$ & $1.24 \pm 0.21^{\mathrm{b}, \mathrm{d}}$ & $2.45 \pm 0.61^{\mathrm{a}, \mathrm{b}, \mathrm{c}}$ \\
Happiness & $10.65 \pm 1.77^{\mathrm{b}, \mathrm{c}, \mathrm{d}}$ & $10.02 \pm 1.94^{\mathrm{a}, \mathrm{c}, \mathrm{d}}$ & $9.37 \pm 2.22^{\mathrm{a}, \mathrm{b}, \mathrm{d}}$ & $7.99 \pm 2.12^{\mathrm{a}, \mathrm{b}, \mathrm{c}}$ \\
Depression & $4.80 \pm 1.75^{\mathrm{b}, \mathrm{c}, \mathrm{d}}$ & $5.92 \pm 1.85^{\mathrm{a}, \mathrm{d}}$ & $5.75 \pm 2.21^{\mathrm{a}, \mathrm{d}}$ & $7.57 \pm 2.35^{\mathrm{a}, \mathrm{b}, \mathrm{c}}$ \\
\hline
\end{tabular}

2 Values represent mean scores \pm SD. $p<0.01$, Bonferroni test: ${ }^{a}$ compared to self-fulfilling; ${ }^{b}$ compared to the high

3 affective; ${ }^{\mathrm{c}}$ compared to the low affective; ${ }^{\mathrm{d}}$ compared to the self-destructive. 


\section{Table 2 (on next page)}

\section{Table 2}

Means in life satisfaction and happiness-increasing strategies among affective profiles in Study II. 
1 Table 2. Means in life satisfaction and happiness-increasing strategies among affective profiles in

2 Study II.

\begin{tabular}{lccccc}
\hline & Self-fulfilling & High affective & Low affective & Self-destructive \\
& $\mathrm{N}=158$ & $\mathrm{~N}=123$ & $\mathrm{~N}=92$ & $\mathrm{~N}=127$ \\
\hline Positive Affect & $3.76 \pm 0.49$ & $3.59 \pm 0.42$ & $2.44 \pm 0.52$ & $2.30 \pm 0.51$ \\
Negative Affect & $1.25 \pm 0.21$ & $2.37 \pm 0.58$ & $1.20 \pm 0.21$ & $2.53 \pm 0.67$ \\
Life satisfaction & $5.17 \pm 1.24$ & $4.11 \pm 1.32$ & $4.42 \pm 1.51$ & $3.15 \pm 1.49$ \\
Social Affiliation & $3.56 \pm 0.53$ & $3.51 \pm 0.42$ & $3.28 \pm 0.63$ & $3.02 \pm 0.67$ \\
Partying and Clubbing & $2.12 \pm 0.71$ & $2.29 \pm 0.75$ & $2.18 \pm 0.67$ & $2.00 \pm 0.64$ \\
Mental Control & $2.12 \pm 0.47$ & $2.43 \pm 0.50$ & $2.20 \pm 0.42$ & $2.59 \pm 0.49$ \\
Instrumental & Goal & $3.47 \pm 0.77$ & $3.51 \pm 0.67$ & $3.07 \pm 0.85$ & $2.92 \pm 0.83$ \\
& & & & \\
Pursuit & & & & \\
Religion & $3.11 \pm 1.19$ & $2.94 \pm 1.04$ & $2.88 \pm 1.11$ & $2.57 \pm 1.02$ \\
Passive Leisure & $3.22 \pm 0.56$ & $3.38 \pm 0.51$ & $3.17 \pm 0.60$ & $3.17 \pm 0.63$ \\
Active Leisure & $3.39 \pm 0.54$ & $3.28 \pm 0.55$ & $3.10 \pm 0.65$ & $2.90 \pm 0.65$ \\
Direct Attempts & $3.91 \pm 0.50$ & $3.68 \pm 0.49$ & $3.60 \pm 0.60$ & $3.27 \pm 0.64$ \\
\hline
\end{tabular}




\section{Table 3 (on next page)}

Table 3

Mean differences in life satisfaction and happiness-increasing strategies between affective profiles. 
1 Table 3. Mean differences, in life satisfaction and happiness-increasing strategies between

2 affective temperaments.

\begin{tabular}{|c|c|c|c|c|}
\hline \multirow[t]{2}{*}{ Affective profiles } & Self-fulfilling & High affective & Low affective & Self-destructive \\
\hline & $N=158$ & $N=123$ & $\mathrm{~N}=92$ & $\mathrm{~N}=127$ \\
\hline \multicolumn{5}{|l|}{ Self-fulfilling } \\
\hline Positive Affect & & $0.17^{*}$ & $1.32 *$ & $1.46^{*}$ \\
\hline Negative Affect & & $-1.12 *$ & $0.05 n s$ & $-1.28 *$ \\
\hline Life satisfaction & & $1.05 *$ & $0.75 *$ & $2.01 *$ \\
\hline Social Affiliation & & $0.05 n s$ & $0.28 *$ & $0.54 *$ \\
\hline Partying and Clubbing & & $-0.16 n s$ & $-0.06 n s$ & $0.12 n s$ \\
\hline Mental Control & & $-0.31 *$ & $-0.09 n s$ & $-0.47 *$ \\
\hline Instrumental & & $-0.04 n s$ & $0.39 *$ & $0.54 *$ \\
\hline \multicolumn{5}{|l|}{ Pursuit } \\
\hline Religion & & $0.17 n s$ & $0.23 n s$ & $0.54 *$ \\
\hline Passive Leisure & & $-0.16 n s$ & $0.05 n s$ & $0.05 n s$ \\
\hline Active Leisure & & $0.11 n s$ & $0.29 *$ & $0.49 *$ \\
\hline Direct Attempts & & $0.24 *$ & $0.31 *$ & $0.64 *$ \\
\hline \multicolumn{5}{|l|}{ High affective } \\
\hline Positive Affect & $-0.17 *$ & & $1.15^{*}$ & $1.29 *$ \\
\hline Negative Affect & $1.11 *$ & & $-1.17 *$ & $-0.16 n s$ \\
\hline Life satisfaction & $-1.05^{*}$ & & $-0.31 n s$ & $0.96^{*}$ \\
\hline Social Affiliation & $-0.05 n s$ & & $0.24 n s$ & $0.50 *$ \\
\hline Partying and Clubbing & $0.16 n s$ & & $0.11 n s$ & $0.29 *$ \\
\hline Mental Control & $0.31 *$ & & $0.23 *$ & $-0.16 n s$ \\
\hline Instrumental & $0.04 n s$ & & $0.43 *$ & $0.58 *$ \\
\hline \multicolumn{5}{|l|}{ Pursuit } \\
\hline Religion & $-0.17 n s$ & & $0.05 n s$ & $0.36 n s$ \\
\hline Passive Leisure & $0.16 n s$ & & $0.21 n s$ & $0.20 n s$ \\
\hline Active Leisure & $-0.11 n s$ & & $0.18 n s$ & $0.38 *$ \\
\hline Direct Attempts & $-0.23^{*}$ & & $0.07 n s$ & $0.40 n s$ \\
\hline \multicolumn{5}{|l|}{ Low affective } \\
\hline Positive Affect & $-1.32 *$ & $-1.15^{*}$ & & $0.14 n s$ \\
\hline Negative Affect & -0.05 & $-1.17 *$ & & $-1.32 *$ \\
\hline
\end{tabular}




\begin{tabular}{|c|c|c|c|c|}
\hline Life satisfaction & $-0.75^{*}$ & $0.31 n s$ & & $1.26^{*}$ \\
\hline Social Affiliation & $-0.28 *$ & $-0.24 n s$ & & $0.26^{*}$ \\
\hline Partying and Clubbing & $0.06 n s$ & $-0.11 n s$ & & $0.18 n s$ \\
\hline Mental Control & $0.09 n s$ & $-0.23 *$ & & $-0.40 *$ \\
\hline Instrumental & $-0.39 *$ & $-0.43^{*}$ & & $0.15 n s$ \\
\hline \multicolumn{5}{|l|}{ Pursuit } \\
\hline Religion & $-0.23 n s$ & $-0.05 n s$ & & $0.31 n s$ \\
\hline Passive Leisure & $-0.05 n s$ & $-0.21 n s$ & & $-0.00 n s$ \\
\hline Active Leisure & $-0.29 *$ & $-0.18 n s$ & & $0.20 n s$ \\
\hline Direct Attempts & $-0.31^{*}$ & $-0.07 n s$ & & $0.33 *$ \\
\hline \multicolumn{5}{|l|}{ Self-destructive } \\
\hline Positive Affect & $-1.46^{*}$ & $-1.29 *$ & $-0.14^{*}$ & \\
\hline Negative Affect & $1.28 *$ & $0.16 n s$ & $1.33 *$ & \\
\hline Life satisfaction & $-2.01 *$ & $-0.96^{*}$ & $-1.26^{*}$ & \\
\hline Social Affiliation & $-0.54 *$ & $-0.50^{*}$ & $-0.26^{*}$ & \\
\hline Partying and Clubbing & $-0.12 n s$ & $-0.29 *$ & $-0.18 n s$ & \\
\hline Mental Control & $0.47^{*}$ & $0.16 n s$ & $0.39 *$ & \\
\hline Instrumental & $-0.54^{*}$ & $-0.58^{*}$ & $-0.15 n s$ & \\
\hline \multicolumn{5}{|l|}{ Pursuit } \\
\hline Religion & $-0.54 *$ & $-0.36 n s$ & $-0.31 n s$ & \\
\hline Passive Leisure & $-0.05 n s$ & $-0.20 n s$ & $0.00 n s$ & \\
\hline Active Leisure & $-0.49 *$ & $-0.38^{*}$ & $-0.20 n s$ & \\
\hline Direct Attempts & $-0.64 *$ & $-0.40^{*}$ & $-0.33^{*}$ & \\
\hline
\end{tabular}

$n s=$ non significant, ${ }^{*} p<0.01$ with Bonferroni Correction. 


\section{Figure 1}

Figure 1

Summary of the results from Study I and II showing the differences between affective profiles in happiness, depression, life satisfaction, and the happiness-increasing strategies. 


\section{High PA}

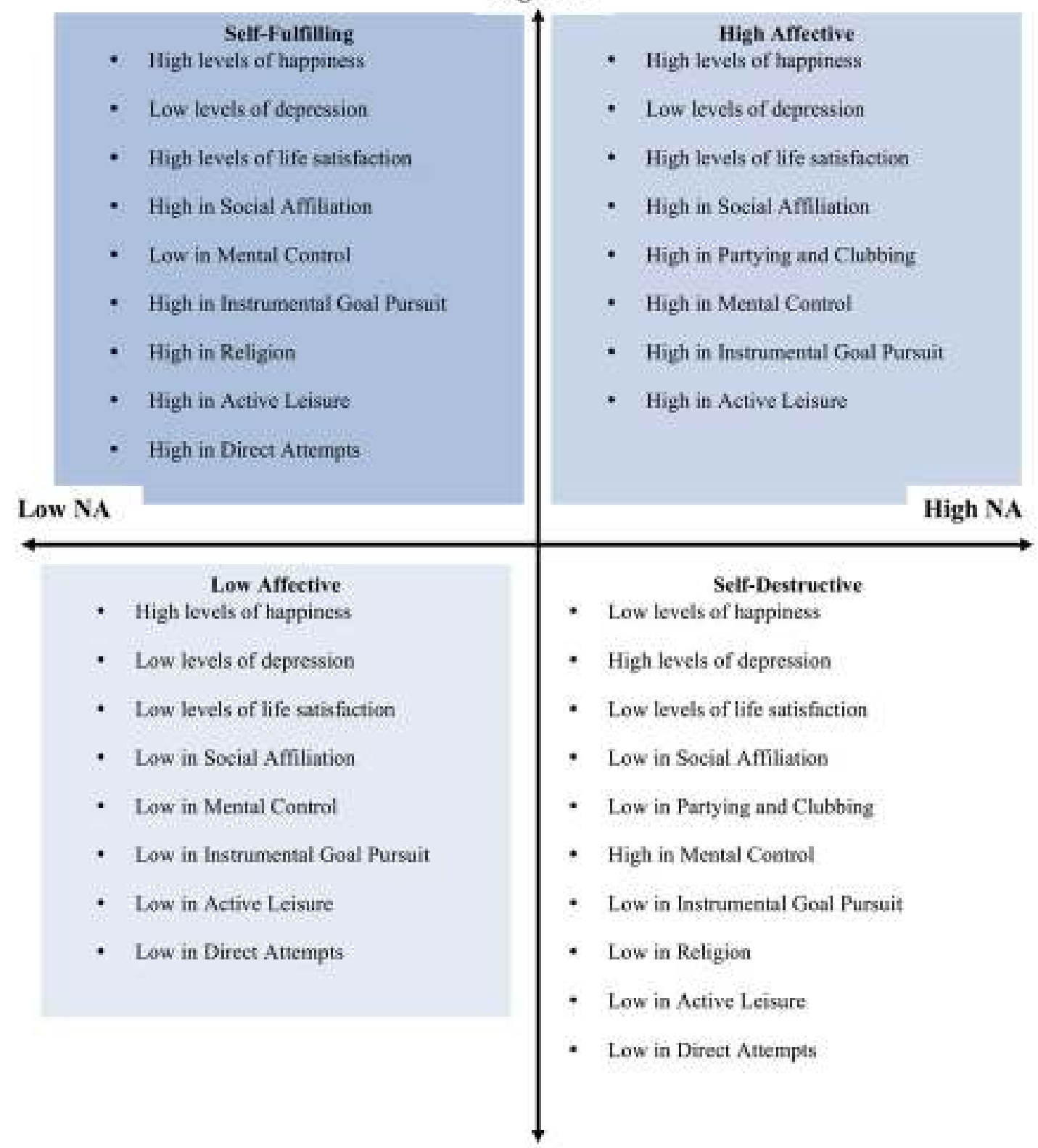

Low PA 